\title{
TIPE GABUNGAN MENDOMINASI JENIS PRE MENSTRUAL SYNDROME (PMS) PADA MAHASISWI TINGKAT I DAN II PRODI DIII KEBIDANANUNUSA
}

\author{
Fauziyatun Nisa' \\ Fakultas Keperawatan dan Kebidanan \\ Universitas Nahdlatul Ulama Surabaya, Jln. Smea 57 Surabaya \\ Email: \\ fauziyatun.nisa@unusa.ac.id
}

\begin{abstract}
Premenstrual syndrome (PMS) is a combination of physical, psychological, and emotional symptoms that relate to the woman's menstrual cycle. The types of this syndrome can be classified according to its symptoms: type $A$ (anxiety), type $H$ (hyperhydration), type $C$ (craving), type $D$ (depression), and the combination of all mentioned types. The objective of this research was to identify the dominant type of PMS experienced by Diploma-III students Program of Study of Midwifery - Fakultas ilmu keperawatan dan kebidanan UNUSA. This research was descriptive by using the cross sectional design. The population involved 245 Diploma-III students Program of Study of Midwifery - UNUSA in 2015-2016. 152 students were taken as the samples by using the probability sampling technique in which the simple random sampling was used. The data collected by using questionnaires and descriptive analysis. Tthe result showed that 56 students experienced PMS type A; 3 students experienced type H; 16 students experienced type $C$, and only one student experienced type D; whereas 76 students experienced the combination of all types which was considered as the dominant. The conclusion was that the female students having PMS would not only experience one type of syndrome, but they might also experience various types at the same time. Hence, they are expected to understand their reproductive health and to get clear information and the right solution when having PMS.
\end{abstract}

Keywords: premenstrual syndrome, types, reproductive health

Abstrak : Pre Menstrual Syndrome atau PMS merupakan kumpulan gejala fisik, psikologis dan emosi perempuan yang terkait dengan siklus menstruasi yang dapat digolongkan menjadi tipe A (Anxiety), tipe $\mathrm{H}$ (Hyperhydration), tipe $\mathrm{C}$ (Craving), tipe $\mathrm{D}$ (Depresion) dan gabungan dari ke empat tipe. PMS dapat mempengaruhi efisiensi dan produktifitas sehari-hari. Tujuan penelitian ini adalah mengidentifikasi tipe PMS yang dominan pada mahasiswi Prodi DIII Kebidanan Fakultas Ilmu Keperawatan dan Kebidanan UNUSA. Desain penelitian secara deskriptif dengan pendekatan cross sectional. Populasinya mahasiswi Prodi D III Kebidanan tahun 2015-2016 dengan jumlah 245 mahasiswa dan sampel penelitian ini 152 mahasiswi diambil secara probability sampling jenis simple random sampling. Instrumen dengan kuesioner. Analisis secara deskriptif. Hasil penelitian didapatkan PMS Tipe A 56 mahasiswi, Tipe H 3 mahasiswi, Tipe C 16 mahasiswi, Tipe D 1 mahasiswi. Tipe gabungan sebanyak 76 mahasiswi. Hasil penelitian menunjukkan bahwa mahasiswi yang sedang mengalami PMS tidak hanya mengalami salah satu dari tipe yang ada, tetapi mereka juga mengalami berbagi macam tipe (gabungan) dalam waktu yang bersamaan. Oleh karena itu pentingnya mahasiswi 
memahami kesehatan reproduksi dan mendapat edukasi tentang cara penanganan yang tepat saat menghadapi PMS.

Kata kunci : Pre Menstrual Syndrome, Tipe PMS, kesehatan reproduksi

\section{PENDAHULUAN}

Masa menstruasi pada perempuan usia reproduksi diwarnai dengan berbagai gangguan kesehatan berupa pusing, depresi dan perasaan sensitif berlebihan. Namun gangguan itu dianggap suatu hal yang wajar, padahal mereka mengalami gangguan yang disebut dengan PMS atau Pre Menstrual Syndrom. PMS dapat menyebabkan kesulitan berkonsentrasi, penurunan minat, pelupa dan menurunnya kemampuan koordinasi yang mengakibatkan menurunnya efisiensi dan produktivitas. Hal itu dapat mempengaruhi aspek sosial ekonomi, rekan kerja, keluarga, dan teman. (Suheimi, 2007).

Ada 200 gejala yang dihubungkan dengan PMS, namun gejala yang paling sering ditemukan adalah iritabilitas atau mudah tersinggung dan disforia atau perasaan sedih. Gejala mulai dirasakan biasanya 7-10 hari menjelang mentruasi berupa gejala fisik maupun psikis yang mengganggu aktivitas sehari-hari dan menghilang setelah menstruasi. Menurut Diana Taylor, guru besar dan direktur Women's Health Program di Department Of Family Health Care Nursing di University of California, San Fransisco terdapat sekitar $95 \%$ perempuan usia reproduktif akan mengalami satu atau lebih gejala itu tepat sebelum periodenya. Gejala lain mulai dari perubahan mood sampai nyeri payudara, bengkak, dan nyeri pinggang. Menurut survey di University Of Arkansas Fayetevill Amerika terhadap 968 perempuan terdapat $90 \%$ perempuan mengalami perubahan mood pramenstruasi dan 89\% mengalami bengkak. Penelitian yang sama menunjukkan bahwa $88 \%$ mengalami nyeri payudara dan tiga perempat kelompok mengalami nyeri pinggang pramenstruasi (Wijaya Kusuma,1999).

Di Indonesia terdapat sekitar 40\% perempuan berusia 14-50 tahun mengalami PMS (Agustini, 2007), bahkan survey tahun 1982 di Amerika Serikat menunjukkan $50 \%$ perempuan mengalami PMS (Wikipedia Indonesia, 2008). Abraham (2007) menjelaskan ada berbagai macam tipe PMS yang dibagi menurut gejalanya yakni : Tipe A (anxiety) ditandai dengan gejala cemas, sensitif,saraf tegang, perasaan labil. Tipe $\mathrm{H}$ (hyperhidration) ditandai dengan gejala perut kembung, nyeri pada payudara. Tipe $\mathrm{C}$ (craving) ditandai dengan rasa lapar, lelah, pusing sampai pingsan. Tipe D (depression) ditandai dengan gejala depresi, ingin menangis, gangguan tidur, pelupa, binggung.

Hasil studi pendahuluan bulan November 2016 pada mahasiswi Prodi DIII Kebidanan Fakultas ilmu keperawatan dan kebidananUNUSA dari 38 responden mengalami PMS dengan berbagai tipe dan gejala diantaranya : kembung 3 orang $(7,9 \%)$, depresi 4 orang $(10,5 \%)$, gangguan konsentrasi 7 orang $(18,4 \%)$, perubahan nafsu makan 14 orang $(36,8 \%)$, letih/pegal 19 orang (50 $\%$ ), jerawat 19 orang $(50 \%)$, nyeri payudara 23 orang $(60,5 \%)$, nyeri perut bagian bawah 26 orang $(68,4 \%)$, mudah tersinggung 28 orang $(73,7 \%)$, perubahan mood 29 orang $(76,3 \%)$.

Perempuan yang mengalami PMS sampai saat ini belum diketahui secara pasti penyebabnya. Gejala ini muncul akibat perubahan hormonal yang berhubungan dengan siklus ovulasi saat menstruasi dan akan menghilang pada 
saat menstruasi dimulai. Teori yang dapat menjelaskan hal tersebut adalah faktor hormonal berupa ketidakseimbangan antara hormon estrogen dan progesteron, dimana hormon estrogen cenderung berlebihan (Sofani, 2008). Ada pula dugaan PMS terjadi akibat kombinasi dari berbagai faktor yang kompleks, salah satunya adalah akibat perubahan hormonal yang terjadi sebelum menstruasi, maupun gangguan metabolisme prostaglandin akibat kurangnya gamma Linolenic Acid (GLA) dan pola hidup yang tidak seimbang (Agustini, 2007).

Tidak ada satupun pengobatan yang efektif bagi semua perempuan yang mengalami PMS karena penyebab PMS hingga kini belum diketahui dan gejala yang bervariasi. Tujuan pengobatan yang utama adalah meredakan gejala yang paling jelas, mengurangi akibat yang timbul dari PMS agar tidak mengganggu aktivitas sehari-hari maupun hubungan interpersonal, serta memberikan dukungan emosional dan pendidikan bagi perempuan.

Tujuan penelitian ini adalah mengidentifikasi tipe PMS yang dominan dirasakan oleh perempuan usia reproduktif pada saat mengalami PMS.

\section{METODE}

Jenis penelitian deskriptif dengan pendekatan cross sectional. Populasinya mahasiswi Prodi D III Kebidanan tahun 2015-2016 dengan jumlah 245 mahasiswa dan sampel berjumlah 152 mahasiswi yang diambil secara probability sampling menggunakan tehnik simple random sampling. Data dikumpulkan melalui kuesioner, dianalisis secara deskriptif.

\section{HASIL DAN PEMBAHASAN 1.Hasil Penelitian}

Tabel 1 Distribusi responden menurut klasifikasi umur pada

\begin{tabular}{|c|c|c|c|}
\hline \multicolumn{4}{|c|}{$\begin{array}{l}\text { mahasiswi Prodi } \\
\text { Kebidanan tahun } 2016\end{array}$} \\
\hline No. & Umur & Frekuensi & Persentase \\
\hline 1. & 18 tahun & 19 & 12,5 \\
\hline 2. & 19 tahun & 54 & 35,5 \\
\hline 3. & 20 tahun & 58 & 38,2 \\
\hline 4. & 21 tahun & 15 & 9,9 \\
\hline 5. & 22 tahun & 6 & 3,9 \\
\hline \multicolumn{2}{|c|}{ Jumlah } & 152 & 100 \\
\hline \multicolumn{4}{|c|}{$\begin{array}{l}\text { Tabel } 1 \text { menunjukkan bahwa sebagian } \\
\text { besar responden berusia } 20 \text { tahun } \\
\text { sebanyak } 58 \text { mahasiswi }(38,2 \%) \text {. }\end{array}$} \\
\hline Tabel 2 & \multicolumn{3}{|c|}{$\begin{array}{l}\text { Distribusi responden menurut } \\
\text { klasifikasi tipe PMS yang } \\
\text { dominan pada mahasiswi DIII } \\
\text { Kebidanan tahun } 2016\end{array}$} \\
\hline No. & $\begin{array}{l}\text { Tipe } \\
\text { PMS }\end{array}$ & Frekuensi & Prosentase \\
\hline 1. & Tipe A & 56 & 36,8 \\
\hline 2. & Tipe $\mathrm{H}$ & 3 & 2,0 \\
\hline 3. & Tipe C & 16 & 10,5 \\
\hline 4. & Tipe D & 1 & 0,7 \\
\hline 5. & $\begin{array}{c}\text { Tipe } \\
\text { gabungan }\end{array}$ & 76 & 50 \\
\hline & & 152 & 11 \\
\hline
\end{tabular}

Tabel 2 menunjukkan bahwa responden yang mengalami PMS sebagian besar tipe gabungan sebanyak 76 mahasiswi (50\%).

\section{Pembahasan}

Hasil penelitian menggambarkan bahwa perempuan yang mengalami PMS rata-rata umur 18-22 tahun. Latar belakang mahasiswi Prodi DIII Kebidanan Fakultas Ilmu Keperawatan dan Kebidanan UNUSA berasal dari lulusan SMU/sederajat, dan ketika mendaftar sebagai mahasiswa baru terdapat ketentuan umur maksimal $\leq 22$ tahun. Pada rentang umur tersebut menunjukkan bahwa mahasiswi tergolong usia subur. BKKBN (1994) menjelaskan bahwa kesuburan bagi seorang perempuan dimulai sejak umur 15-49 tahun, berstatus kawin maupun yang belum kawin dan masih mengalami menstruasi. Adiningsih (2004) menjelaskan bahwa banyak sekali 
perempuan yang mengalami keluhan saat menjelang ataupun saat menstruasi, tetapi mereka masih enggan memeriksakan diri pada petugas kesehatan terutama pada perempuan dewasa muda. Mereka lebih sering mencari informasi dari luar atau yang beredar di masyarakat, oleh karena itu pentingnya pendidikan kesehatan terutama masalah kesehatan reproduksi remaja sehingga mereka dapat memahami dan menjaga kesehatan reproduksinya serta mendapatkan solusi yang tepat bila mengalami masalah kesehatan reproduksi.

Hasil penelitian ini menunjukkan bahwa PMS yang dialami oleh mahasiswi sebagian besar tipe gabungan, walaupun secara teori pada umumnya perempuan merasakan tipe A. Agustini (2007) menjelaskan bahwa terdapat sekitar $40 \%$ perempuan berusia 14-50 tahun di Indonesia mengalami PMS dan menurut Abraham (2007) tipe PMS dapat dibagi menurut gejalanya menjadi 4 macam : yaitu tipe A (anxiety) sekitar 80\%, tipe $\mathrm{H}$ (hyperhydration) sekitar $60 \%$, tipe $\mathrm{C}$ (craving) sekitar 40\%, tipe D (depression) sekitar 20\%.

$$
\text { Hasil penelitian inipun }
$$

menunjukkan bahwa gejala yang dirasakan oleh perempuan yang mengalami PMS bervariasi, tidak hanya merasakan gejala dari 1 tipe, tetapi dapat merasakan berbagai gejala secara bersamaan dari masing-masing tipe yang ada, sehingga tipe yang muncul pun dapat bervariasi atau gabungan dari beberapa tipe, bahkan kemungkinan keempat tipe dapat muncul dalam waktu yang bersamaan. Abraham (2007) menjelaskan bahwa PMS tipe D berlangsung bersamaan dengan tipe A, hanya sekitar 3\% dari seluruh tipe PMS yang murni tipe $\mathrm{D}$.

Ditinjau dari segi umur, secara teori PMS lebih terlihat jelas pada perempuan yang berumur 30-45 tahun. Hasil penelitian ini sebagian besar umur 20 tahun, sehingga PMS yang terjadi tidak hanya terfokus pada satu tipe namun lebih banyak mengalami gejala dari berbagai tipe secara bersamaan. Hal ini dapat terjadi karena gejala yang dirasakan tiap individu berbeda tergantung tingkat sentivitas atau kepekaan perempuan terhadap perubahan hormonal dalam siklus menstruasi. Wikipedia Indonesia (2007) menjelaskan bahwa ada faktor yang dapat meningkatkan risiko terjadinya PMS diantaranya paritas, status perkawinan, usia, stres, diet, kekurangan zat gizi terutama vitamin B dan kegiatan fisik.

\section{KESIMPULAN}

Hasil penelitian menunjukkan bahwa sebagian besar responden mengalami PMS tipe gabungan. Gangguan fisik dan mental yang terjadi pada saat PMS bervariasi mulai dari ringan sampai berat dengan gejala yang berbeda pada tiap individu tergantung tingkat sensitifitas.

Oleh karena itu penting bagi mahasiswa memahami kesehatan reproduksi dan permasalahannya agar dapat menerapkan cara yang tepat saat menghadapi PMS.

\section{DAFTAR PUSTAKA}

Anurogo dan Wulandari.(2011). Cara Jitu Mengatasi Nyeri Haid. Yogyakarta, ANDI

Arikunto.(2006). Prosedur Penelitian Suatu Pendekatan Praktek. Jakarta, Rineka Cipta

Asrinah, Jamingatu S, Suciyati.(2011). Menstruasi dan

Permasalahannya. Yogyakarta, Pustaka Penasea

Bobak.(2004). Buku Ajar Keperawatan Maternitas. Jakarta, EGC

Kumalasari, Intan.(2012). Kesehatan Reproduksi Untuk Mahasiswa Kebidanan dan Keperawatan. Jakarta, Salemba Medika 
Kusmiran, Eny.(2011). Kesehatan Reproduksi Remaja Dan Wanita. Jakarta, Salemba Medika

Laila, Nur Najmi.(2011). Buku Pintar Menstruasi. Yogyakarta, Buku Biru.

Manuaba, IBG.(2008). Gawat-Darurat Obstreti-Ginekologi dan ObstretiGinekologi untuk Profesi Bidan. Jakarta, EGC

Manuaba, Sri Kusuma Dewi Suryasaputra, dkk.(2009). Buku Ajar Ginekologi

Untuk Mahasiswa Kebidanan. Jakarta, EGC

Morgan, Geri, dkk.(2009). Obstetri Dan Ginekologi Paduan Praktik Ed. 2. Jakarta, EGC

Notoatmodjo.(2010). Metodelogi Penelitian Kesehatan. Jakarta, Rineka Cipta

Nursalam.(2011). Konsep dan Penerapan Metodologi Penelitian Ilmu Keperawatan:Pedoman Skripsi, Tesis dan Instrumen Penelitian Keperawatan. Jakarta, Salemba Medika.

Nursalam.(2013). MetodologiPenelitian Ilmu Keperawatan ed. 3. Jakarta, Salemba Medika

Perry dan Potter.(2005). Keterampilan dan Prosedur Dasar. Jakarta, EGC

Purnomo, Windhu.(2007). Hand Out/ Metodologi Penelitian Kuantitatif. Surabaya, FKM Unair

Proverawati dan Misaroh.(2009). Menarche Menstruasi Pertama Penuh Makna. Yogyakarta, Nuha Medika

Sarwono, P.(2005). Ilmu Kandungan. Edisi 2 cetakan IV. Jakarta, Yayasan Bina Pustaka. 